\title{
Tubular complexes as a source for islet neogenesis in the pancreas of diabetes-prone BB rats
}

\author{
Gen-Sheng Wang ${ }^{1}$, Lawrence Rosenberg ${ }^{2}$ and Fraser W Scott ${ }^{1}$ \\ ${ }^{1}$ The Ottawa Health Research Institute, University of Ottawa, Ottawa, Canada and ${ }^{2}$ Department of Surgery, \\ McGill University, Montreal, Canada
}

\begin{abstract}
Tubular complexes (TC) in the pancreas contain duct-like structures with low cuboidal or flattened cells surrounding a large lumen and are thought to be a response to pancreatic injury. TC have been studied in animal models of chemical or surgically induced pancreatic damage but their occurrence has not been reported in rodent models of spontaneous autoimmune type I diabetes. We hypothesized that TC would be increased during the active phase of islet destruction in autoimmune diabetes and could contain islet progenitor cells. We analyzed TC in pancreas of Wistar Furth (WF), control (BBC) and diabetes-prone BioBreeding (BBdp) rats using immunohistochemistry and morphometry. TC were observed in all rat strains during active pancreas remodeling ( $\sim 13$ days). They increased between 60 and 93 days only in BBdp rats coincident with the increase in diabetes cases. Most TC were infiltrated with $\mathrm{CD}^{+}{ }^{+}$T-cells. Duct-like cells in the TC had low expression of the exocrine marker amylase, increased expression of epithelial cell markers, keratin and vimentin, and remarkably high cell proliferation and cell death. TC islets contained cells stained positive for insulin, glucagon, somatostatin, pancreatic polypeptide, as well as PDX-1, chromogranin, and hepatocytederived growth factor receptor, c-met. Transitional cells that were keratin ${ }^{+} /$insulin $^{+}$and keratin ${ }^{+} /$amylase $^{+}$ cells were present in TC. The stem cell marker, nestin was upregulated in the TC region. Duct-like cells in TC of BBdp rats expressed markers of committed endocrine precursors: PDX-1, neurogenin 3 and protein gene product 9.5. This study demonstrates that TC are upregulated during $\beta$-cell destruction and contain potential endocrine progenitors.
\end{abstract}

Laboratory Investigation (2005) 85, 675-688, advance online publication, 14 March 2005; doi:10.1038/labinvest.3700259

Keywords: tubular complex; transdifferentiation; stem cell; islet neoformation; type I diabetes

Although a majority of $\beta$-cells in the pancreas of animals and humans with overt type I diabetes is destroyed, there are still islets that appear normal, without infiltrating immune cells, and containing insulin. Newly diagnosed patients display greater insulin secretory response to a mixed meal than was previously appreciated ${ }^{1}$ and in some patients, complete loss of insulin secretory capacity occurs as late as 2 years after diagnosis. This suggests there are processes that attempt to compensate for the loss of islet $\beta$-cell mass even in the immune-targeted pancreas. ${ }^{2}$ However, the presence of islet $\beta$-cell regenerative processes in individuals that develop

Correspondence: Dr FW Scott, PhD, Ottawa Health Research Institute, Molecular Medicine, 501 Smyth Road, Ottawa, Ont., Canada K1H 8L6.

E-mail: fscott@ohri.ca

Received 16 November 2004; revised and accepted 26 January 2005; published online 14 March 2005 spontaneous autoimmune diabetes remains an open question.

Pancreatic $\beta$-cells undergo a very slow renewal process after birth, but remodeling does occur in neonates and it can be reactivated after pancreatic injury. ${ }^{3}$ Recent studies suggest that transdifferentiation from other cell types also contributes to islet renewal, ${ }^{4}$ but this concept remains controversial. ${ }^{5,6}$ Thus, pancreatic $\beta$-cell renewal is more frequent than previously thought and occurs by different pathways that are not well understood.

One of these pathways is the formation of ductlike tubular structures called tubular complexes (TC) in the exocrine pancreas. Normal pancreas has a tubular arrangement early in life. ${ }^{7}$ TC have been observed in several conditions involving pancreatic damage or stress such as pancreatitis, ${ }^{8}$ duct ligation, ${ }^{9}$ partial pancreatic duct obstruction by wrapping, ${ }^{10}$ chemically induced carcinogenesis, ${ }^{11-13}$ $90 \%$ pancreatectomy, ${ }^{14}$ and chronic hyperglycemia induced by glucose infusion. ${ }^{15}$ It is commonly 
accepted that TC formation in the pancreas is the result of acinar to duct dedifferentiation. ${ }^{4,11,16-18}$ In vitro studies also demonstrated that acinar cells from humans and animals can transform into ductlike cells by dedifferentiation. ${ }^{19-22}$ Thus, TC have been considered to be a general reaction of acinar cells to damage ${ }^{23}$ that results in acinar to duct dedifferentiation. ${ }^{5,11}$ TC have been observed in the Long-Evans rat model of type II diabetes, ${ }^{24}$ but they have not been reported in rodent models of spontaneous type I diabetes.

We hypothesized that formation of TC may be increased during the active phase of islet destruction and these structures could contain progenitor cells. We analyzed for the presence of TC in Wistar Furth (WF), BioBreeding control (BBc) and type I diabetes-prone $\mathrm{BB}(\mathrm{BBdp})$ rats, characterized them with respect to constituent cell types and defined the temporal relationship to diabetogenesis. Phenotypic characterization of the TC revealed duct-like acinar cells that are centers of intense cell proliferation and apoptosis, displaying markers of endocrine progenitors.

\section{Materials and methods}

\section{Animals and Diets}

BBdp rats develop insulitis around the beginning of adolescence at 50 days of age and it is well established by 70 days when diabetic cases are beginning to appear. Diabetes occurs between 55 and 130 days and the mean age at onset is around 90 days. BBc (diabetes-resistant control) and BBdp rats were purchased from the Animal Resources Division of Health Canada (Contact: Jocelyn Souligny@hc-sc.gc.ca), and Wistar Furth (WF) rats were purchased from Charles River, Laval, Quebec, Canada. Rats aged 7-153 days were maintained under specific pathogen-free conditions. Animals were weaned at day 23 onto cereal-based diets and tested twice weekly for glucose in the urine after 60 days of age. Diabetes was diagnosed if fasting blood glucose was greater than $11.1 \mathrm{mM}$. Animals without clinical signs of diabetes at the time of killing were designated asymptomatic. Animals were killed by exsanguination while under $3 \%$ isoflurane in oxygen anesthesia. Pancreata were fixed in Bouin's solution, embedded and serial sections $(5 \mu \mathrm{m})$ were cut.

\section{Immunohistochemistry}

Since TC are rare in younger animals, immunohistochemistry was performed mostly on pancreatic sections from older animals. Sections were stained for insulin, glucagon, chromogranin (marker for neuroendocrine cells), somatostatin, pancreatic polypeptide, amylase (acinar cell marker), proliferating cell nuclear antigen (PCNA), keratin, cytokeratin 20 (CK20), and vimentin (epithelial cell markers), neurogenin 3 (Ngn3; transcription factor expressed in islet endocrine progenitor cells), pancreatic and duodenal homeobox gene-1 (PDX1), hepatocyte growth factor receptor (HGF/c-met; marker for islet neogenesis), glucagon-like peptide 1 receptor (GLP-1R; receptor for GLP-1 involved in islet neogenesis), nestin (intermediate filament protein, putative marker for pancreatic stem cells), protein gene product 9.5 (PGP9.5, a putative marker for pancreatic stem cells), and CD3 (a T-lymphocyte surface marker). Primary antibodies and the means of antigen retrieval are shown in Table 1. Some sections were heated in $0.01 \mathrm{M}$ citric acid buffer at pH 6.0 in a microwave oven for $10 \mathrm{~min}$ to retrieve antigen. For keratin, CK20 and vimentin staining, digestion of tissue sections with $0.1 \%$ pronase $\mathrm{E}$ for $5 \mathrm{~min}$ was applied. For insulin staining, goat antirabbit IgG conjugated to alkaline phosphatase (DAKO Diagnostics, Canada), was used as a

Table 1 Primary antibodies

\begin{tabular}{|c|c|c|c|c|}
\hline Antigen & Species & Antibody source & Dilution & Antigen retrieval \\
\hline Insulin & Guinea pig & DAKO Diagnostics Canada Inc. & $1: 150$ & Not applied \\
\hline Glucagon & Rabbit & DAKO Diagnostics Canada Inc. & $1: 8000$ & Not applied \\
\hline Somatostatin & Rabbit & DAKO Diagnostics Canada Inc. & $1: 3200$ & Not applied \\
\hline Pancreatic polypeptide & Rabbit & DAKO Diagnostics Canada Inc. & $1: 9600$ & Not applied \\
\hline Chromogranin & Rabbit & Research Diagnostics Inc. & $1: 400$ & Not applied \\
\hline Amylase & Goat & Santa Cruz Biotechnology Inc. & $1: 1600$ & Not applied \\
\hline PCNA & Mouse & DAKO Diagnostics Canada Inc. & $1: 100$ & Microwave \\
\hline Keratin, wide spectrum & Rabbit & DAKO Diagnostics Canada Inc. & $1: 800$ & Pronase E \\
\hline Vimentin & Mouse & DAKO Diagnostics Canada Inc. & $1: 800$ & Microwave \\
\hline Cytokeratin 20 & Mouse & DAKO Diagnostics Canada Inc. & $1: 200$ & Pronase E \\
\hline PDX-1 & Rabbit & Gift from Dr Chris Wright, Vanderbilt U. & $1: 10000$ & Microwave \\
\hline Neurogenin 3 & Rabbit & Gift from Dr Michael German, UCSF & $1: 100$ & Microwave \\
\hline C-met & Rabbit & Santa Cruz Biotechnology Inc. & $1: 100$ & Microwave \\
\hline Nestin & Mouse & The Developmental Studies Hybridoma Bank, U. of Iowa & $1: 100$ & Microwave \\
\hline GLP-1R & Rabbit & Gift from Dr Daniel Drucker, U. Toronto & $1: 3200$ & Microwave \\
\hline PGP9.5 & Mouse & ABcam Inc. & $1: 300$ & Microwave \\
\hline CD3 & Rabbit & ABcam Inc. & $1: 800$ & Microwave \\
\hline
\end{tabular}


secondary antibody diluted 1:40 and developed for $10 \mathrm{~min}$ in the dark with 5-bromo-4-chloro-3-indoxyl phosphate and nitro blue tetrazolium chloride (BCIP/NBT, DAKO Diagnostics, Canada) as the substrates. Biotinylated rabbit anti-mouse IgG (DAKO Diagnostics, Canada) was used as a secondary antibody for PCNA, vimentin, CK20, PGP9.5, and nestin staining. Diaminobenzidine (DAB, Sigma Chemical Co., MO, USA) at $0.06 \%$ and $\mathrm{H}_{2} \mathrm{O}_{2}$ at $0.03 \%$ were used as substrate. Biotinylated goat anti-rabbit IgG (DAKO Diagnostics, Canada) was used as a secondary antibody for keratin, c-met, chromogranin, Ngn3, glucagon, somatostatin, pancreatic polypeptide, GLP-1R, PDX-1, CD3 staining and DAB was used as a substrate. Biotinylated multilink swine anti-goat, mouse, rabbit IgG (DAKO Diagnostics, Canada) was used as a secondary antibody for amylase staining. In addition, a Catalysed Signal Amplification kit (DAKO) was used for staining Ngn3. For all assays, omitting the primary or secondary antibody resulted in no staining.

Triple immunofluorescent staining was performed on paraffin sections fixed with Bouin's solution. Sections were heated in $0.01 \mathrm{M}$ citric buffer (pH 6.0, microwave, $10 \mathrm{~min}$ ) followed by $10 \mathrm{~min}$ incubation with $0.05 \%$ pronase $\mathrm{E}\left(22^{\circ} \mathrm{C}\right)$. Sections were incubated with goat anti-amylase antibody overnight at $4^{\circ} \mathrm{C}$ followed by incubation with rabbit antikeratin antibody for $2 \mathrm{~h}\left(22^{\circ} \mathrm{C}\right)$. AMCA-conjugated donkey anti-goat antibody and FITC-conjugated donkey anti-rabbit antibodies (1:200) were applied together for $30 \mathrm{~min}$ at $22^{\circ} \mathrm{C}$; incubated with guinea-pig anti-insulin antibody for $2 \mathrm{~h}$ at $22^{\circ} \mathrm{C}$ followed by incubation with rhodamine-conjugated donkey antiguinea pig antibody (1:400) for $30 \mathrm{~min}$. Fluorescent images were viewed using a Zeiss LSM 410 laser scanning microscope equipped with FITC (505 nm), rhodamine red $(565 \mathrm{~nm})$, and AMCA $(400 \mathrm{~nm})$ filters. Sections incubated with secondary antibodies alone were used as negative controls. Coincident fluorescent signals observed using all three filters were considered to be autofluorescence.

\section{Insulitis}

All morphometric analyses were performed on coded samples. H\&E-stained sections were evaluated at a magnification of $\times 200$ and confirmed at $\times 400$ magnification. Subjective overall rating of pancreatic inflammation was performed as described. ${ }^{25}$

\section{Identification of Tubular Complexes}

Two H\&E sections at least $120 \mu \mathrm{m}$ apart were examined for TC. TC were identified based on reduced zymogen granules characterized by decreased eosin-stained area containing more than four ductules, and composed of duct-like acinar cells.

\section{Image Analysis and Morphometry}

All morphometric analyses were performed on coded samples. Image analysis was performed using a Zeiss Axioplan2 microscope and a computer using Northern Eclipse software (Empix, Mississauga, Canada) as described in detail elsewhere. ${ }^{26}$

\section{Proliferation in Islets, Acinar, Duct, and Duct-Like Acinar Cells}

On each PCNA, insulin double-stained section, cell nuclei labelled in dark brown (S-phase) were regarded as $\mathrm{PCNA}^{+}$on images taken at $\times 400$. Cells with light brown nuclei (G1 phase) or with cytoplasmic staining (G2-phase) were not counted..$^{27}$ Most ductal cells and duct-like acinar cells and approximately 1000 acinar cells, were counted on each section. The cell proliferation index was defined as the percentage of PCNA ${ }^{+}$cells in each population. The number of islet cells in each crosssectional area of islet was deduced by dividing the total islet area by the average endocrine cell size $\left(150 \mu \mathrm{m}^{2}{ }^{26}\right)$.

\section{Apoptosis in Endocrine and Exocrine Tissue}

Using H\&E- stained sections and a magnification of $\times 400$, apoptosis in islet cells and acinar tissues was identified based on chromatin condensation, cellular shrinkage from adjacent cells and formation of distinct membrane-bound vesicles with or without chromatin inside. The TUNEL technique (In situ Cell Death Detection Kit, Roche Diagnostics GmbH, Germany) was used to verify the presence of apoptotic cells.

\section{Islet Neogenesis and Adult Progenitor Cells in Tubular Complexes}

Islet neogenesis has been described as the formation of new islets from precursor or progenitor cells. ${ }^{28} \mathrm{In}$ the present study, it was evaluated based on the expression of c-met, ${ }^{29} \mathrm{Ngn} 3,{ }^{30} \mathrm{PDX}-1$ and insulin on duct-like cells in the TC. C-met, is a receptor for hepatocyte growth factor (HGF/c-met) that has been used as a marker for sorting adult pancreatic stem cells $^{31}$ and was upregulated during islet neogenesis. $^{32}$ Ngn3, a basic helix-loop-helix transcription factor, has been reported to play an important role in the development of the pancreas. ${ }^{3-35}$ PDX-1, pancreatic duodenal homeobox-1 gene, is essential in the early development of the pancreas and later maturation of $\beta$-cells. Nestin is an intermediate filament protein that has been identified as a marker for multipotent stem cells in the central nervous system and in the pancreas. ${ }^{36,37}$ PGP9.5 is a member of the ubiquitin carboxyl-terminal hydrolase isozyme family expressed in mature neurons. It is expressed in embryonic pancreas, in normal adult 
pancreatic islets and duct-like acinar cells of pancreatic duct-ligated rats ${ }^{38,39}$ and is thought to be a marker for endocrine progenitors. Antibodies for PDX-1, Ngn3, nestin and PGP9.5 were used to identify TC progenitor cells.

\section{Statistics}

Data are expressed as mean \pm s.d. ANOVA and LSD test were used to compare the significance of differences between means. Fisher's exact test was used for comparison between ratios. $P$-values less than 0.05 were considered to be statistically significant.

\section{Results}

\section{Characteristics of Tubular Complexes}

Typical TC had enlarged acinar lumina and acinar cell height was decreased (Figure 1a and b). Ductlike cells in the TC had fewer zymogen granules compared to acinar cells in the non-TC region. The diameter of TC ranged from 146 to $1145 \mu \mathrm{m}$ and the area of the TC ranged from 16789 to $1029238 \mu \mathrm{m}^{2}$ occupying $0.18 \pm 0.21 \%(n=23)$ of pancreatic section area. Some animals had more than one TC on a single section. The number of islets encountered in the TC area ranged from 0 to 7 . The insulin ${ }^{+}$area in the TC region occupied $19.0 \pm 13.4 \%(n=4)$ which was substantially greater than the insulin ${ }^{+}$area of the entire pancreas $(1.0 \pm 0.3 \%)$ in the present study $(n=12, P=0.0001)$. Most of the islets found in the TC region of 70-120 days BBdp rats showed abnormal morphology, appeared distorted, with hypertrophy, cell death, and infiltration with mononuclear cells. In asymptomatic BBdp rats aged older than 145 days, islets appeared normal. Islets in the TC region tended to be smaller than islets outside the TC $\left(7502 \pm 7704\right.$ vs $13919 \pm 4834 \mu \mathrm{m}^{2}$, respectively, $P=0.07, n=8$ ). Inflammatory cells were encountered inside or around the TC in animals older than 45 days (Figure 1b) and were observed in the majority of the islets in diabetic rats, with high insulitis rating of $3-4$. In diabetic rats, insulin ${ }^{+}$cells were usually absent in the islets associated with TC. Insulin $^{+}$cells in the TC were present in only $1 / 7$ diabetic compared with $16 / 23$ asymptomatic rats $(P=0.02)$, suggesting they were targeted by the autoimmune attack. No mononuclear cells infiltrated the TC (Figure 1c) in 14 days BB rats.

\section{Cell Proliferation and Apoptosis in Tubular Complexes}

H\&E sections were evaluated for apoptotic bodies as defined by morphological features and confirmed using the TUNEL assay. Apoptotic bodies were found in TC and in the surrounding area. Figure $1 \mathrm{~d}$ shows several apoptotic bodies with condensed chromatin in a TC. Apoptotic bodies were much more prevalent in the TC area than in acinar tissue in the non-TC area (Table 2). TUNEL $^{+}$cells were more frequent in the TC region (Figure 1e) than in the non-TC acinar tissue. Apoptotic bodies were frequently found in islets associated with TC or in non-TC regions in diabetic pancreas but were not observed in TC islets of asymptomatic BBdp rats older than 145 days.

PCNA $^{+}$cells with dark brown nuclei were considered to be in S-phase of the cell cycle. By this criterion, many acinar cells were in S-phase, but there were few duct cells and even fewer islet cells in S-phase. PCNA ${ }^{+}$cells in the TC region (Figure 1f) were much more frequent than in surrounding nonTC acinar tissues and ductal cells (Figure $1 \mathrm{~g}$ and $\mathrm{h}$, Table 2). Two PCNA ${ }^{+} \beta$-cells were observed in a TCislet (Figure 1f inset). TC also contained insulin ${ }^{+}$ clusters and small islets (Figure 1h). The percentage of PCNA $^{+}$duct-like cells in the TC was much greater than that of PCNA ${ }^{+}$duct cells or acinar cells in the non-TC region (Table 2). The percentage of $\mathrm{PCNA}^{+}$islet cells inside the TC was greater than that of the islets outside of TC $(P<0.05)$. The absence of apoptotic bodies and increased expression of PCNA in the islets within the TC region indicates a shift toward islet cell renewal. Mitotic figures were frequently observed in acinar cells in younger animals, rarely observed in acinar cells from adults, but were encountered in the TC-region in eight out of $24 \mathrm{TC}$ from adult pancreas.

\section{Frequency of TC in WF, BBc and BBdp Rats}

TC were not present in the pancreas of all three rat types at 7 days of age (Figure 2). By 13 days, TC were observed in a small proportion of WF, BBC and BBdp rats but were absent in older WF or BBc rats. TC were observed in one diabetic rat as early as 56 days. TC were identified in $10-36 \%$ of BBdp rats (both asymptomatic and diabetic) beginning at $\sim 60$ days and paralleled development of diabetes. By 93 days, the mean age of onset of diabetes, $36 \%$ of BBdp animals had one or more TC. The majority of

Figure 1 TC structure, apoptosis and cell proliferation in pancreata from BBdp rats. (a, b) Typical TC (arrow head) from a diabetic BBdp rat, 97 days; (c) a TC in a BBc rat, 14 days; (d) mononuclear cell infiltration and apoptotic bodies (arrows) in a TC of an asymptomatic

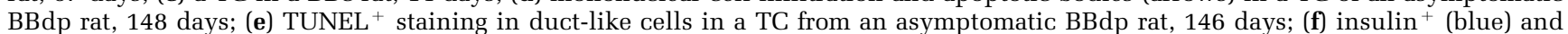
PCNA $^{+}$(brown) cells, asymptomatic BBdp rat, 151 days. Inset shows two PCNA ${ }^{+} \beta$-cells (arrows) in a TC-islet; (g) two PCNA ${ }^{+}$duct cells (arrows) on the same section in (f); (h) insulin ${ }^{+}$(blue) and PCNA $^{+}$(brown) cells in asymptomatic BBdp rat pancreas, 153 days. Bar $=250 \mu \mathrm{m}$ in $\mathbf{a}$ and $\mathbf{f} ; 50 \mu \mathrm{m}$ in $\mathbf{b}, \mathbf{e}, \mathbf{g}, \mathbf{h} ; 25 \mu \mathrm{m}$ in $\mathbf{c}$ and $\mathbf{d}$. 
a

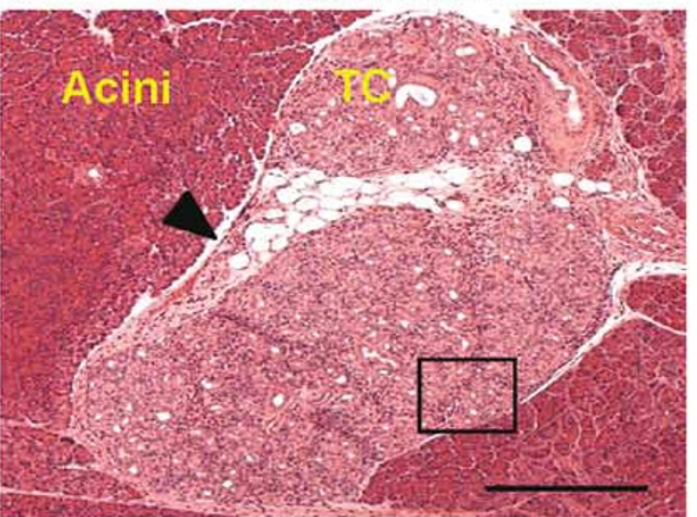

c

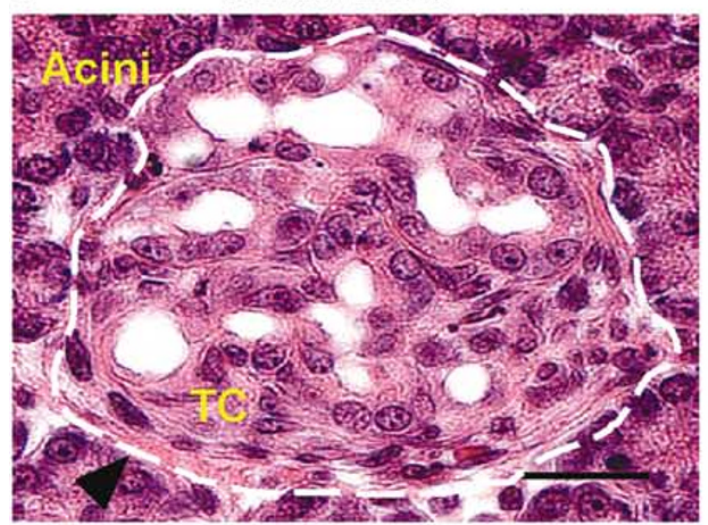

e

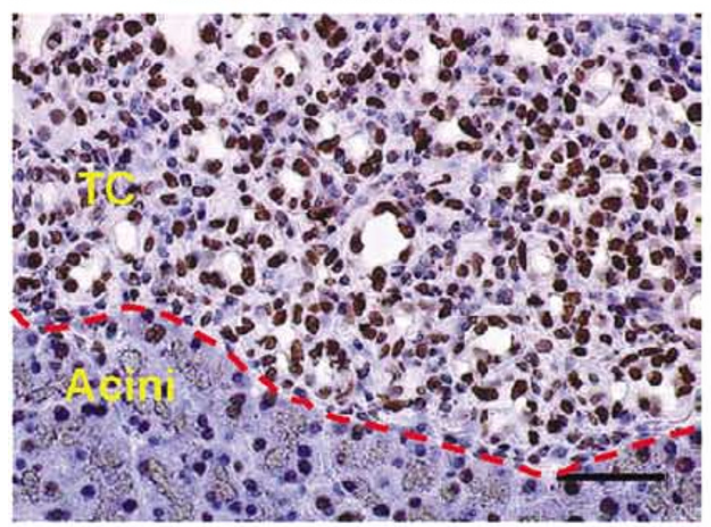

g

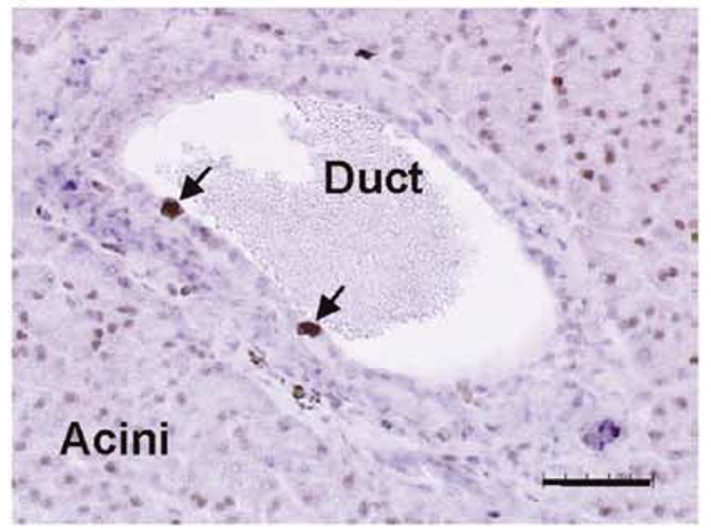

b Enlargement of square in (a)
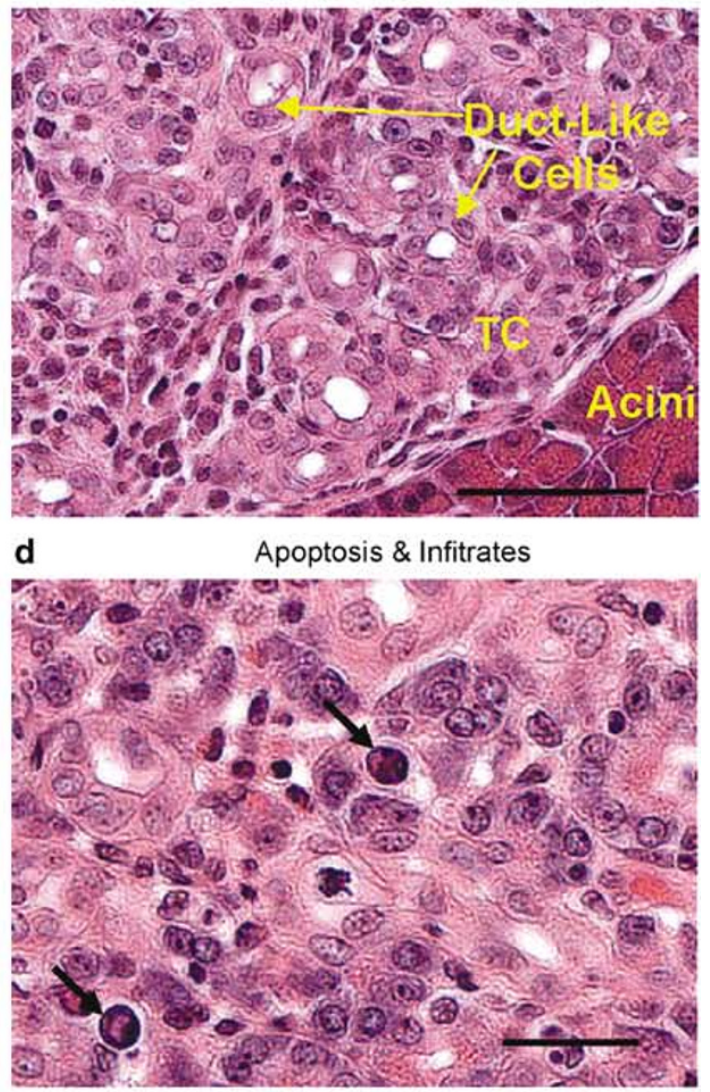

f

$\mathrm{PCNA}^{+} /$Insulin ${ }^{+} \beta$-Cells in TC

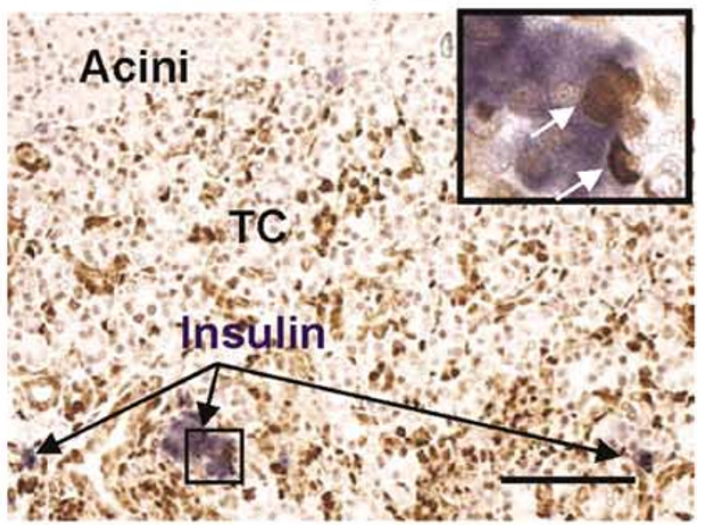

h

$\mathrm{PCNA}^{+}$Duct-Like Cells in TC

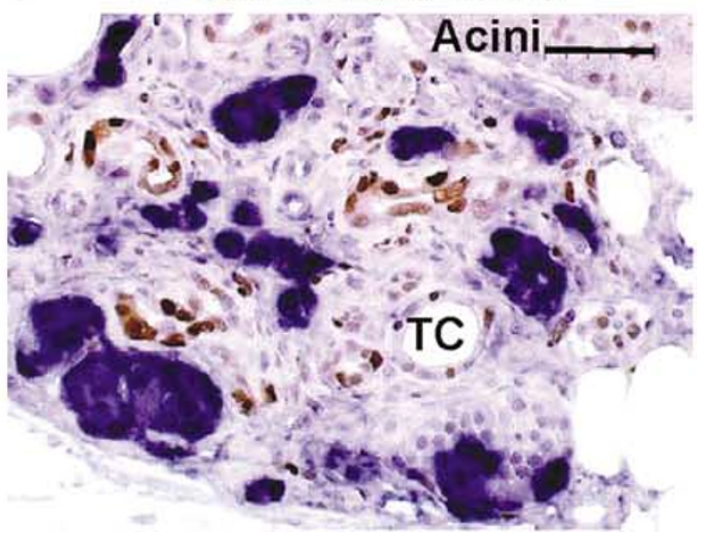


Table $2 \mathrm{PCNA}^{+}$cells and apoptotic bodies in pancreatic acinar tissue, islets, ducts and duct-like acinar cells in the TC and non-TC region in asymptomatic BBdp rats aged $\sim 150$ days

\begin{tabular}{|c|c|c|c|c|c|}
\hline & \multicolumn{2}{|r|}{$T C$} & \multicolumn{2}{|c|}{ Non-TC } & \multirow[b]{2}{*}{ Acinar } \\
\hline & Islets & Duct-like acinar cells & Islets & Duct & \\
\hline $\begin{array}{l}\mathrm{PCNA}^{+} \text {cells }(\%) \\
\text { Apoptotic bodies } / \mathrm{cm}^{2}\end{array}$ & $6.63 \pm \frac{7.09}{0}$ & $\begin{array}{l}16.66 \pm 9.23 \\
3520 \pm 210^{* *}\end{array}$ & $\begin{array}{l}0.62 \pm 0.61 \\
\quad 4 \pm 2\end{array}$ & $1.41 \pm 0.48^{* * *}$ & $\begin{array}{l}2.34 \pm 0.48^{* * *} \\
\quad 8 \pm 5\end{array}$ \\
\hline
\end{tabular}

$n=7 ;{ }^{*} P<0.05$ vs non-TC islets, ${ }^{* *} P<0.001$ vs acinar cells and ${ }^{*}{ }^{*} P<0.01$ vs duct-like acinar cells in TC

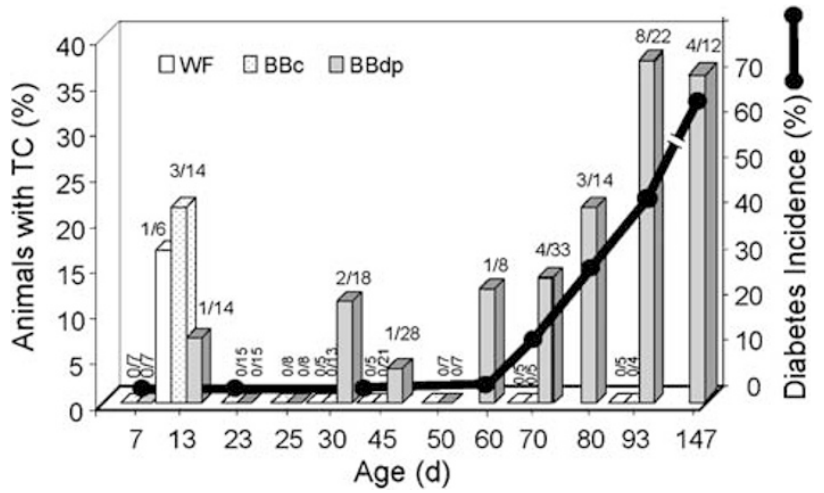

Figure 2 Frequency of TC in WF, BBc and BBdp rats. Line graph shows normal course of diabetes development in the Ottawa colony of BBdp rats based on six experiments $(n=169$ rats); final diabetes incidence, $65.3 \pm 14.9 \%$. Frequency of animals with TC is shown over each bar.

diabetes cases in $\mathrm{BB}$ rats develop between 60 and 125 days. By 147 days, 33\% of the remaining asymptomatic BBdp rats had TC, all of which were infiltrated by inflammatory cells. TC occurred in asymptomatic and overt diabetic rats with similar frequencies and there was no sex-related difference.

\section{Phenotype of Cells in TC}

There were insulin ${ }^{+}$and glucagon ${ }^{+}$cells in islets, both inside and outside of the TC (Figure 3a). Pancreatic polypeptide ${ }^{+}$and somatostatin ${ }^{+}$cells were also identified in TC-islets (Figure $3 \mathrm{~b}$ and c). Insulin staining was generally absent in islets within the pancreatic TC of overt diabetic rats. Adjacent sections stained for insulin, glucagon, somatostatin and pancreatic polypeptide were analyzed. Single endocrine cells in TC-islets did not show staining for more than one hormone suggesting these cells were mature. Amylase is universally expressed in the exocrine pancreas. It was stained in acinar-like cells in some tubules in the TC region but was not stained in many duct-like cells (Figure $3 \mathrm{~d}$ ) in the TC region, suggesting an early stage of TC formation. Chromogranin A and B, markers for neuroendocrine cells, were strongly stained at the periphery of islets and weakly stained in the core of normal islets. Single chromogranin ${ }^{+}$cells were more frequent in the TC area compared with the surrounding acinar or duct cells (Figure 3e).

The epithelial marker, keratin was universally stained in ductal epithelium. Keratin was also stained in duct-like cells in the TC (Figure 3f, arrow), but staining was not seen in the acinar cells in the non-TC region. CK20, a subtype of keratin, was expressed on ductal epithelium in the non-TC region (Figure 3g on right) but duct-like acinar cells were not stained (Figure $3 g$ on left). Vimentin, another epithelial marker that is increased during islet neogenesis in the pancreas, was also intensely stained in duct-like cells in the TC vs the non-TC region (Figure $3 \mathrm{~h}$ ). The staining of keratin and vimentin on duct-like acinar cells in the TC area indicates transdifferentiation from acinar cells into duct-like cells.

Figure 4 shows triple staining for insulin, keratin and amylase in two asymptomatic BBdp rats aged 146 and 149 days. Figure 4a shows the staining pattern in the non-TC region in the pancreas. Keratin $^{+} /$amylase $^{-}$cells were frequently observed in the TC region (Figure 4b). Figure 4c demonstrates the presence of keratin $^{+} /$amylase $^{+}$cells (arrow head) and insulin ${ }^{+} /$keratin $^{+}$cells (arrows) in a TC

Figure 3 Endocrine, neuroendocrine, epithelial and acinar cell markers in TC of BBdp rats (a) Insulin ${ }^{+}$(blue) and glucagon ${ }^{+}$(brown) cells in pancreas from an asymptomatic BBdp rat, 153 days; (b) insulin (purple) and pancreatic polypeptide (brown) staining; 149 days asymptomatic BBdp rat; (c) adjacent section to (b) stained for insulin (purple) and somatostatin (brown); (d) Amylase ${ }^{+}$cells, 146 days asymptomatic BBdp rat; Normal acinar cells stained uniformly for amylase, whereas TC 'acinar units' displayed duct-like cells that were amylase $^{+}$(open arrow), amylase ${ }^{-}$(arrow head) or a mixture (filled arrow) of these two cell populations; (e) chromogranin ${ }^{+}$cells in asymptomatic BBdp rat TC including chromogranin ${ }^{+}$islet; (f) keratin staining, asymptomatic BBdp rat, 151 days. Note, some duct-like cells were keratin $^{+}$(arrow); (g) CK 20 staining, 148 days asymptomatic BBdp rat; (h) vimentin stained intensely in the duct-like cells in the TC (inset in $\mathbf{h}$ ), but acinar cells surrounding the TC were negative in a diabetic rat at 97 days. Bar $=50 \mu \mathrm{m}$ in $\mathbf{a}, \mathbf{b}, \mathbf{c}, \mathbf{e}, \mathbf{g}$, and $\mathbf{h} ; 250 \mu \mathrm{m}$ in $\mathbf{d}$; and $100 \mu \mathrm{m}$ in $\mathbf{f}$. 
a

Insulin+Glucagon

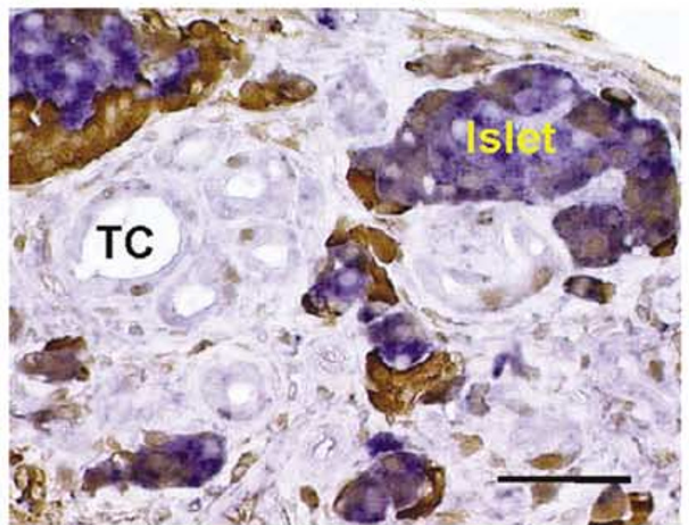

c

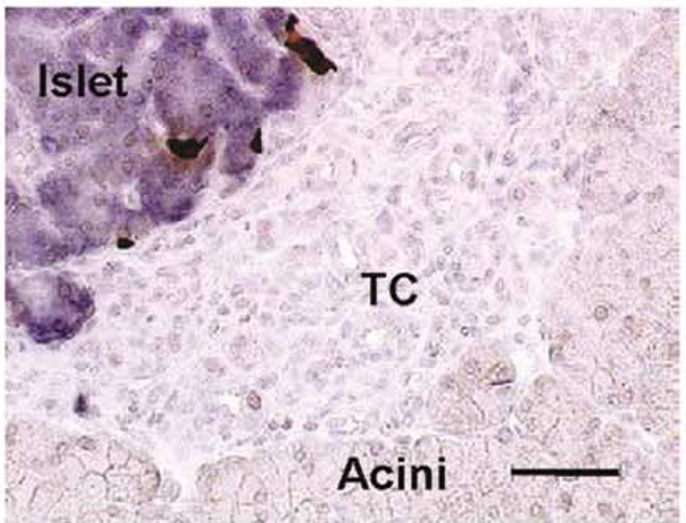

e
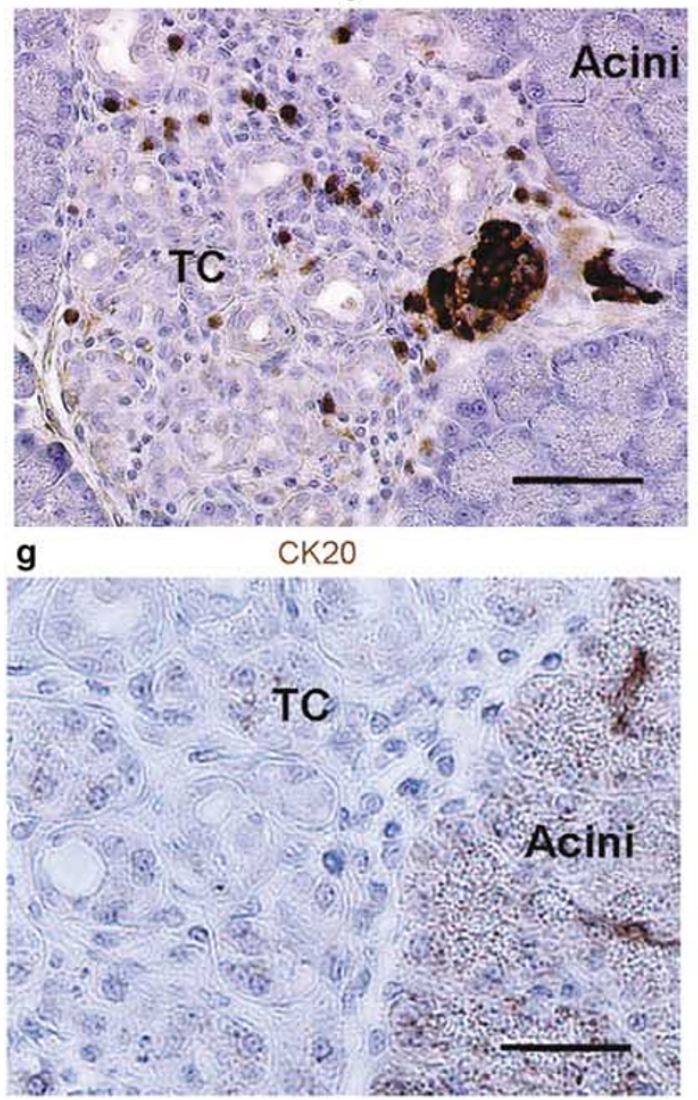

b

Insulin+Pancreatic Polypeptide

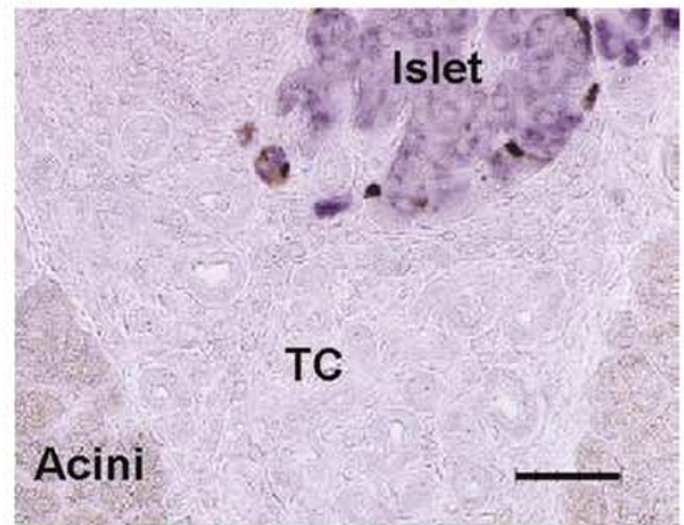

d
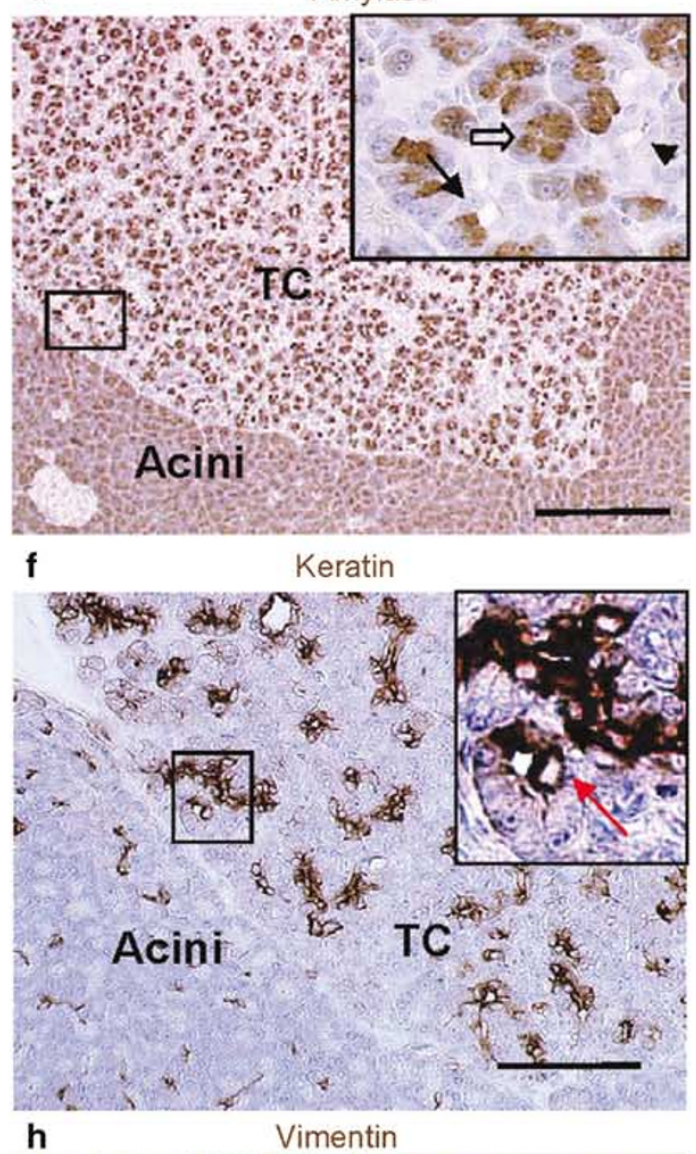

h

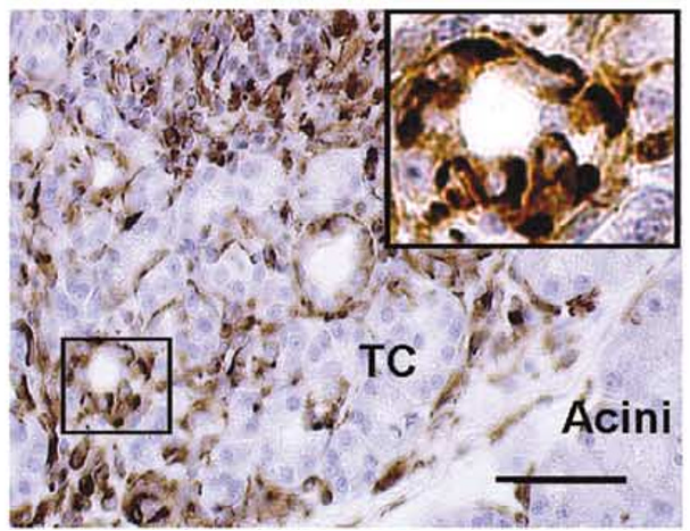


a Keratin $^{+}$, amylase ${ }^{+}$or insulin ${ }^{+}$cells in non- $\mathrm{TC}$ region

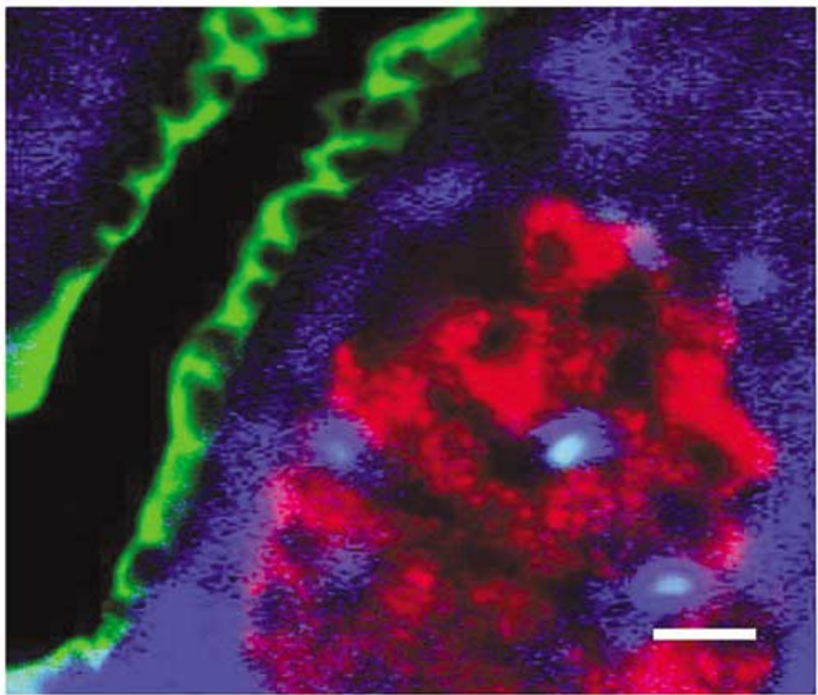

C

Keratin $^{+} /$insulin+ ${ }^{+}$or keratin+/amylase ${ }^{+}$ duct-like cells in TC

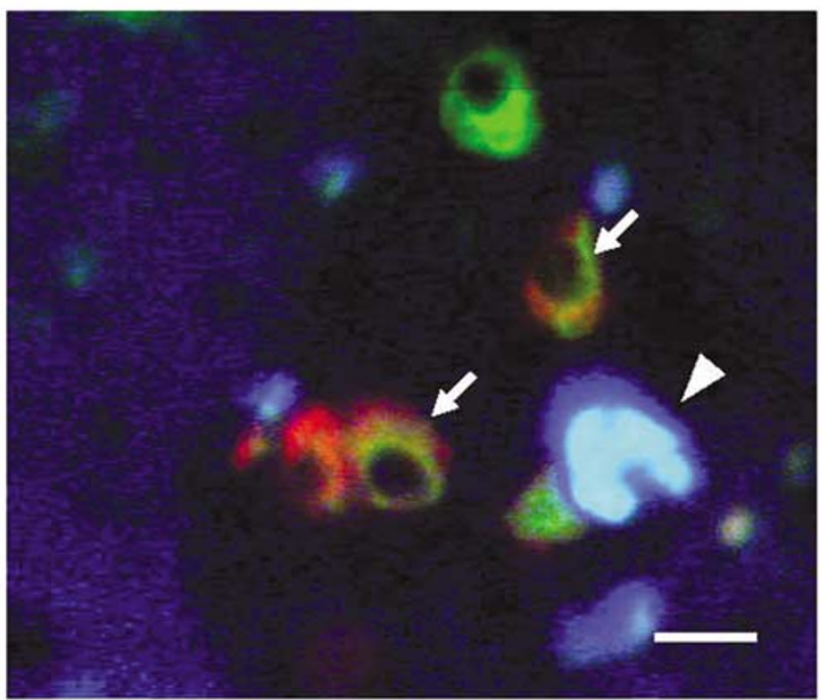

b

Keratin $^{+} /$amylase $^{-}$duct-like cells in TC

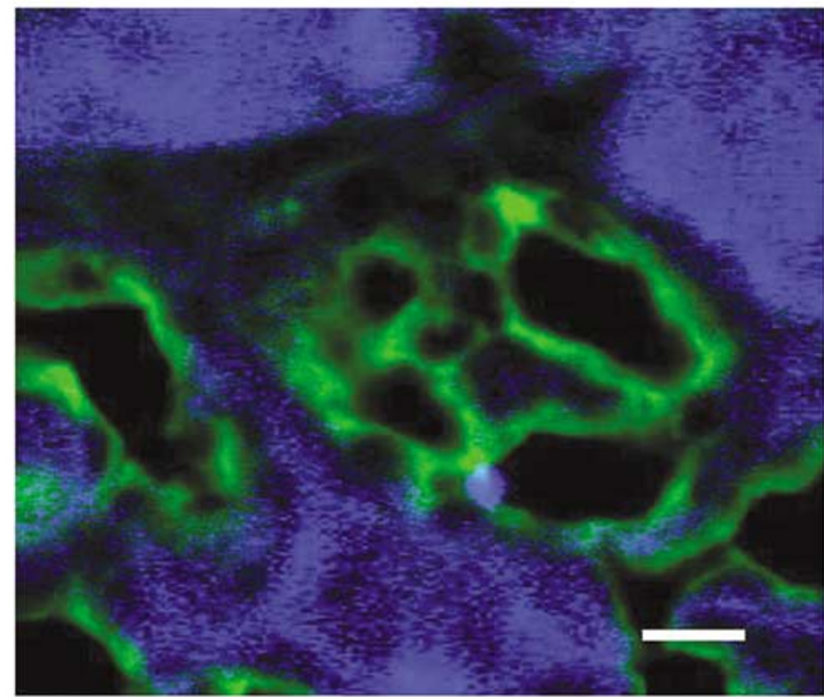

d

Insulin ${ }^{+}$cells associated with keratin+/amylase- duct-like cells

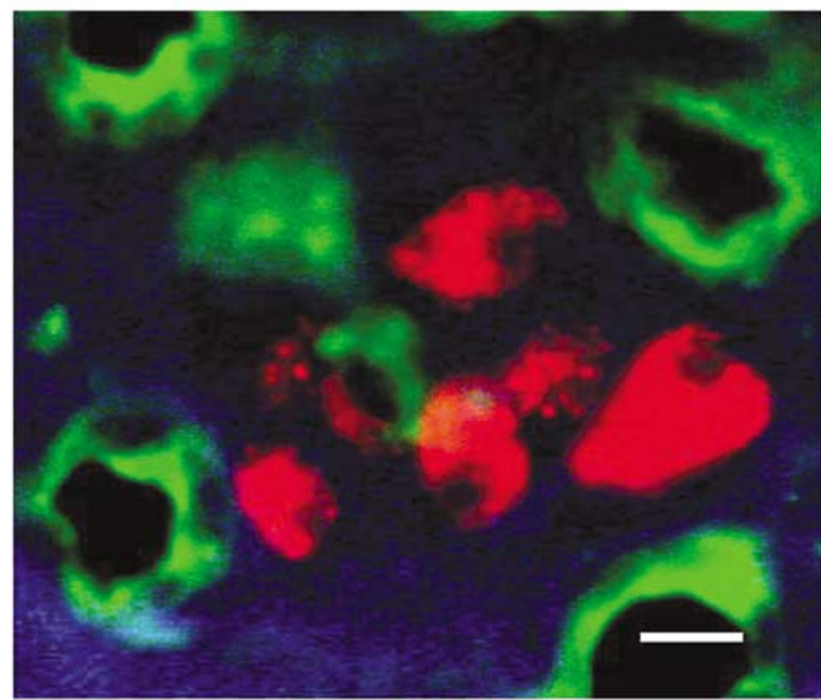

Figure 4 Triple staining of insulin, keratin and amylase in TC of BBdp rats. Fluorescent staining for insulin (red), keratin (green), amylase (blue) on cells in TC from asymptomatic BBdp rats, aged 146 and 149 days is shown. (a) Triple staining of insulin, keratin and amylase in the non-TC region of BB rat pancreas, (b) Keratin ${ }^{+} /$amylase $^{-}$duct-like cells were observed in the TC region. (c) Keratin ${ }^{+}$/ insulin $^{+}$(arrows) and keratin ${ }^{+} /$amylase $^{+}$(arrow head) duct-like cells were present in the TC. (d) Insulin ${ }^{+}$cells associated with

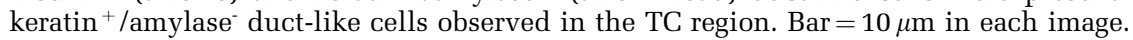

from a 149 day asymptomatic BBdp rat, which indicates intermediate cells are present in the TC region and could be undergoing transdifferentiation towards a $\beta$-cell phenotype. Intact insulin ${ }^{+}$ cells were also observed in the TC (Figure $4 \mathrm{~d}$ ), further supporting the possibility of $\beta$-cell neogenesis from TC. Insulin ${ }^{+} /$amylase $^{+}$cells were not observed.

PDX-1 was stained in the nuclei of islet $\beta$-cells, regardless of location in the pancreas, either in the TC region or in the non-TC region. PDX-1 staining was also localized in some duct cells. PDX-1 ${ }^{+}$cells were identified in duct-like TC cells (Figure 5, red arrow in a, d and e). Several PDX-1 ${ }^{+}$clusters $(\leq 4$ cells) were observed inside the TC. Of particular note, the PDX $-1^{+}$cell in Figure $5 \mathrm{~d}$ and e (red arrow) appeared to be budding from duct-like cells.

\section{Islet Neogenesis and Growth Factor Receptor Expression in TC}

C-met ${ }^{+}$cells were observed at the periphery of islets outside (Figure 6a) and inside of TC (Figure 6b), 


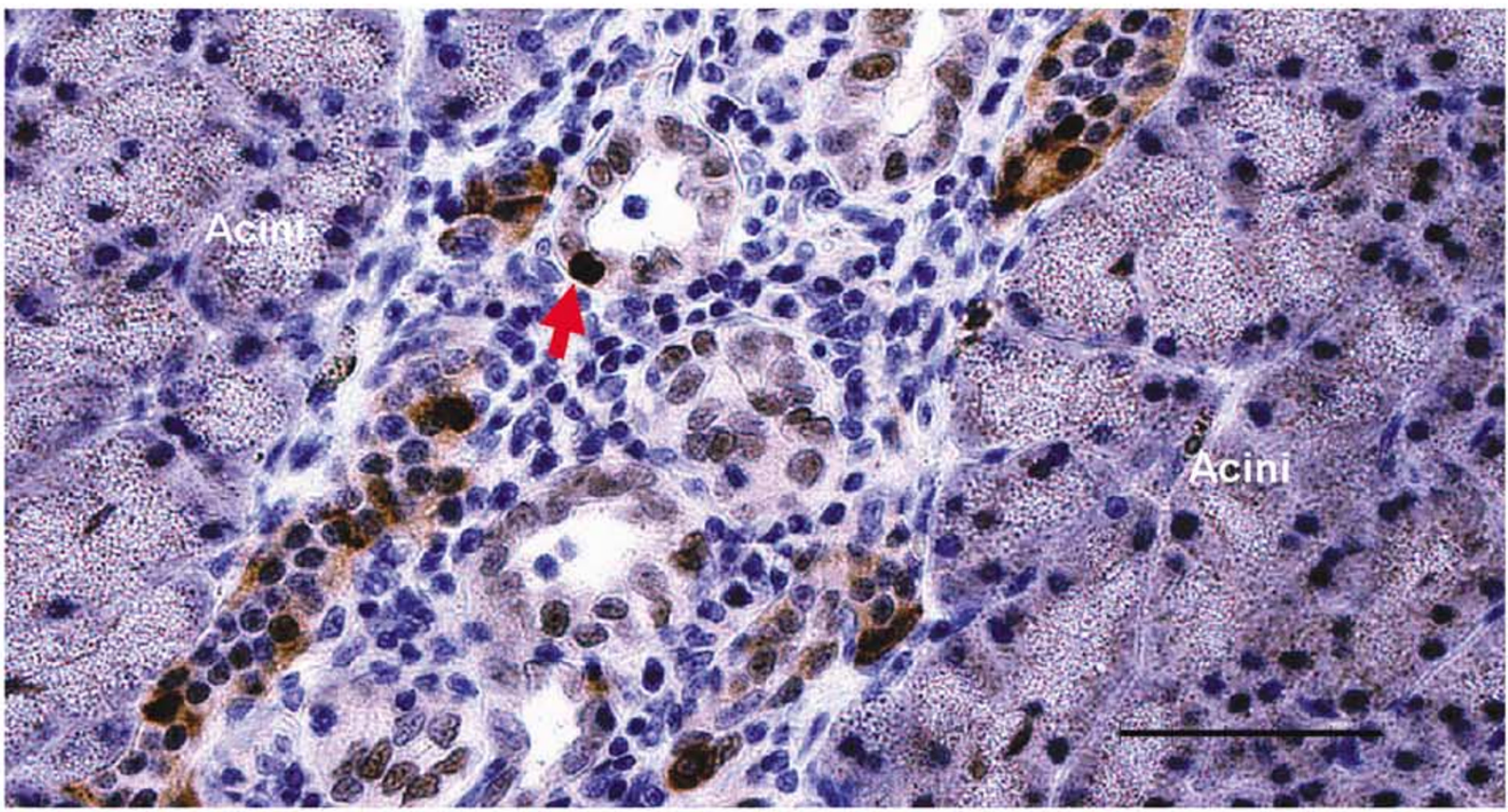

b

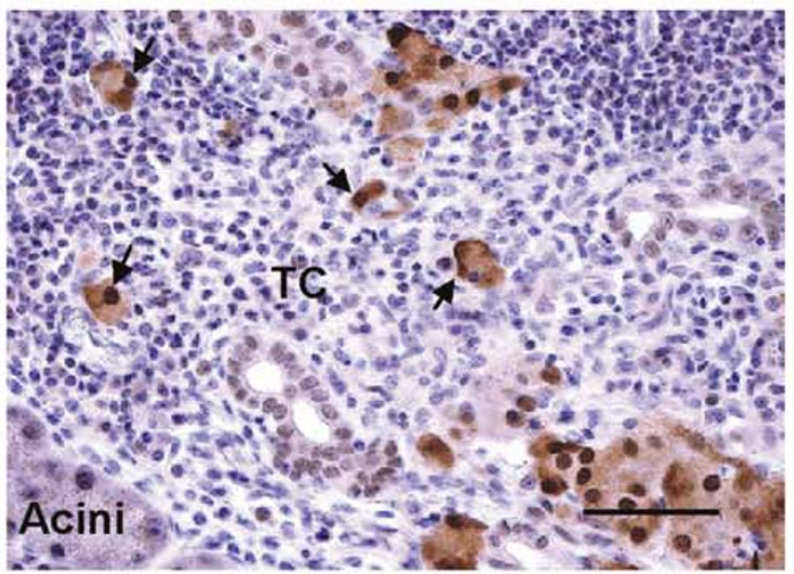

d

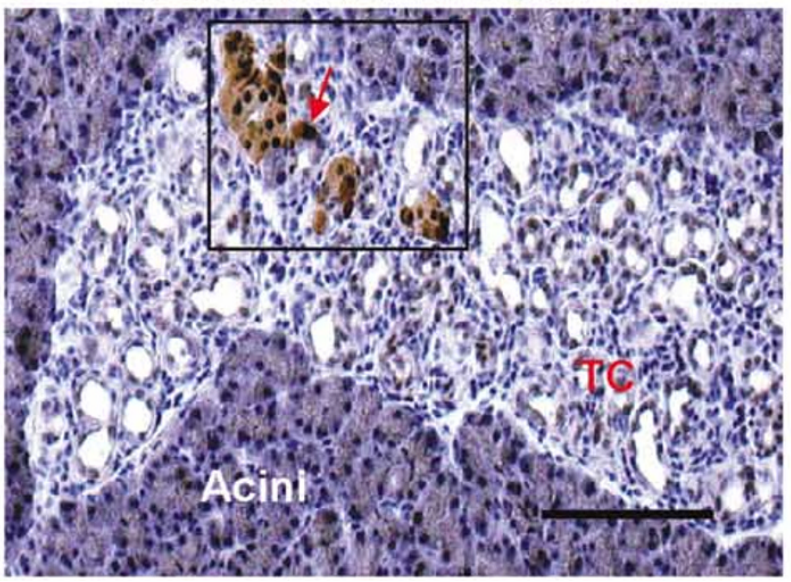

C

PDX $-1^{+}$cells budding from TC

\section{e Enlargement of the box in (d)}

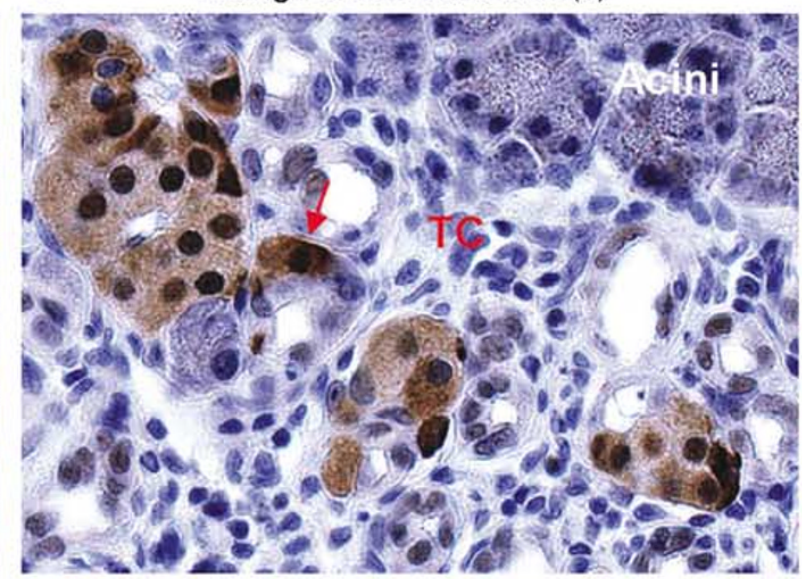

Figure 5 PDX $-1^{+}$cell clusters and PDX-1+ duct-like cells inside TC. (a-e) Asymptomatic BBdp rats at 150, 147, 150, 146, 146 days PDX$1^{+}$duct-like cells (red arrow in a, $\mathbf{d}$ and $\mathbf{e}$ ). PDX-1 ${ }^{+}$cell in $\mathbf{d}$ and $\mathbf{e}$ (red arrow) appears to be budding from duct-like cells. Several PDX-1 clusters ( $\leq 4$ cells) were observed in the TC (black arrows, b, c). Mononuclear cell infiltration was present in most of the TCs. Bar $=50 \mu \mathrm{m}$ in each image. 
mainly on glucagon ${ }^{+}$cells. Duct-like cells in the TC region were not positive for C-met. GLP-1R, receptor for the mainly gut-derived neuroendocrine hormone, glucagon-like peptide 1 (GLP-1) was stained on $\alpha$ - and $\beta$-cells in the islets inside or outside of the TC, but no staining was observed in duct-like cells in the TC (data not shown). Ngn3 is a transcription factor expressed in pancreatic endocrine progenitor cells during early embryogenesis ${ }^{40}$ and possibly in adult pancreas. ${ }^{41,42} \mathrm{Ngn} 3$ was stained in islets of 15 day embryonic pancreas using the ABC method, but was not detectable by this method in neonatal or adult pancreas. However, using a Catalysed Signal Amplification kit, we detected Ngn3 in normal adult islets. Ngn3 was not only present in islets of adult pancreas as shown in Figure 6c, but was also in duct-like cells in the TC (Figure 6c and d), indicating that Ngn3 may be involved in differentiation of duct-like cells into endocrine cell progenitors.

\section{Identification of Nestin ${ }^{+}$Cells in TC}

Nestin is a marker for multipotent stem cells in the central nervous system and in the pancreas. ${ }^{36} \mathrm{We}$ observed nestin staining in islets, ductules and blood vessels of young BB rats, 7-30 days of age. In older BB rats $\sim 100$ days, nestin was observed mainly in islets with mononuclear cell infiltration and was not observed around ducts (data not shown). In adults, nestin expression was also localized between tubule-like structures in the TC region, but was not observed in the non-TC region. Duct-like cells were not stained for nestin as shown in Figure 6e.

\section{Identification of PGP9.5 ${ }^{+}$Cells in TC}

We observed PGP9.5 on neuronal cells and endocrine cells in the pancreas. A few duct cells were positive for PGP9.5. Interestingly, several PGP9.5 ${ }^{+}$ duct-like cells were also identified in the TC region as shown in Figure 6f.

\section{Infiltration of $\mathrm{CD3}^{+} \mathrm{T}$ cells in $\mathrm{TC}$}

Anti-CD3 antibody was used to label T lymphocytes. T-cell infiltration into islets was found in BBdp rats as early as 45 days of age. CD ${ }^{+}$cell infiltration into (non-TC) islets was frequently found in asymptomatic BBdp rats and diabetic rats. There were few $\mathrm{CD}^{+}$cells in the acinar area across all ages. CD3 ${ }^{+} \mathrm{T}$ cells were also observed in the TC of asymptomatic and diabetic rats. Immune cells were sometimes in close proximity to insulin ${ }^{+}$cells in the TC of asymptomatic rats (Figure 7a). However, insulin ${ }^{+}$ cells were usually absent in TC from diabetic rats (Figure $7 \mathrm{~b}$ ), although some $\mathrm{CD}^{+}{ }^{+}$cells remained.

\section{Discussion}

Most previous studies were performed using animals in which pancreatic injury by chemical or surgical intervention was used to induce TC. In the present study, we analyzed the spontaneous appearance of TC during the natural course of pancreatic inflammation and development of autoimmune diabetes. This study provides evidence of a compensatory process in diabetes-prone rats that is increased during the active phase of $\beta$-cell damage and involves remodeling and transdifferentiation in TC. First, cell turnover in the TC region was much more active than in the non-TC region, mainly in duct-like cells (Figure $1 \mathrm{~d}-\mathrm{f}, \mathrm{h}$ ) as reflected by increased cell proliferation and apoptosis, indicating that duct-like cells in the TC region were actively remodeling. Increased expression of PCNA in TC-islets but not in islets in the non-TC exocrine pancreas, further showed that cell renewal is favored in TC islets. Second, TC increased more than three-fold in older diabetes-prone or overt diabetic $\mathrm{BB}$ rats but not in $\mathrm{BBc}$ or WF rats and there was a close association between islet damage and TC formation (Figure 2). The appearance of TC is likely a default process during pancreas remodeling early in life and our results show that this process is reactivated during the course of islet injury. Third, the duct-like cells in the TC region were keratin ${ }^{+}$ and vimentin ${ }^{+}$, with fewer amylase ${ }^{+}$cells compared with exocrine tissue, indicating transformation toward epithelial cells. Fourth, the appearance in the TC of keratin ${ }^{+} /$insulin ${ }^{+}$and PDX-1 ${ }^{+}$cells, one of which was budding from a duct-like cell, is consistent with transdifferentiation towards a $\beta$-cell phenotype (Figure 4c). Finally, insulin ${ }^{+}$cells were more frequent in TC from asymptomatic rats compared with diabetic rats.

In studies of the early kinetics of chemically induced pancreas damage, Bockman et $a{ }^{11}{ }^{11}$ and Reid and Walker ${ }^{43}$ showed that immature TC were characterized by the presence of both acinar and duct cell markers. In later stages (2 weeks to 9 months) of pancreatic damage, ${ }^{12}$ TC were characterized by increased keratin expression and absence of acinar cell markers. In our study,

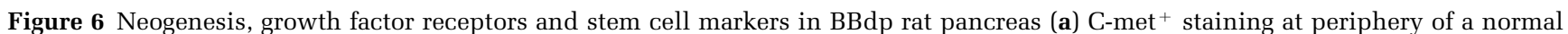
islet, 28 days BBc rat; (b) C-met ${ }^{+}$staining in TC islets (red dashed lines), but not in duct-like cells, 149 days asymptomatic BBdp rat; (c, d) Ngn3 expression mainly in duct-like cells of TC (open arrows), a few nuclei (solid arrows) in an islet (dashed line in c) localized adjacent to a TC, 149 days asymptomatic BBdp rat; (e) a few nestin ${ }^{+}$cells (brown) were situated between ductule-like structures in TC, asymptomatic BBdp rat, 148 days; (f) PGP9.5 ${ }^{+}$duct-like cells (arrow) in a TC, asymptomatic BBdp rat, 148 days. Note: one small islet (open arrow) and a neuronal cell (arrow head) were also stained. Bar $=25 \mu \mathrm{m}$ in a, f; $50 \mu \mathrm{m}$ in b, $\mathbf{c} ; 20 \mu \mathrm{m}$ in e. 
TC-duct-like cells showed reduced zymogen granules, decreased amylase staining and increased staining with ductal cell markers. Once the TC is formed, some cells could be multipotent and differentiate back into acinar cells or forward into islet cells or duct cells depending on the stimuli a

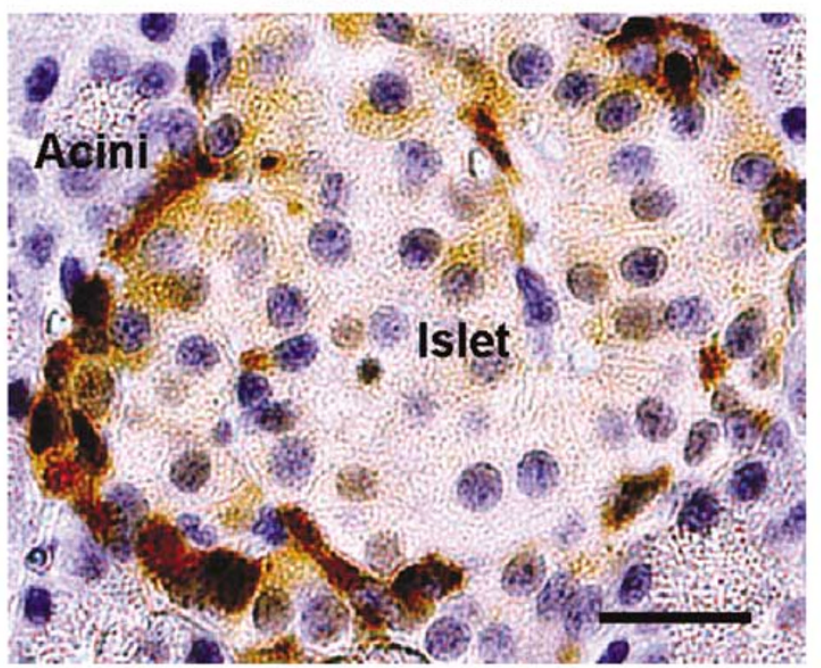

C

Ngn3 in an Islet and TC

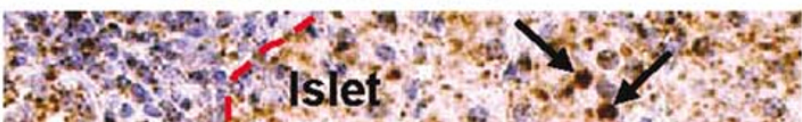

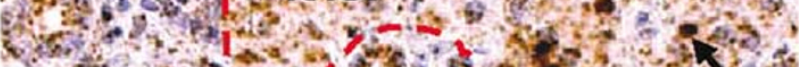

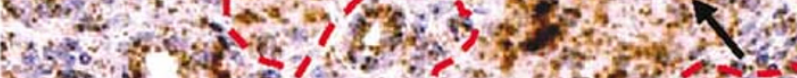

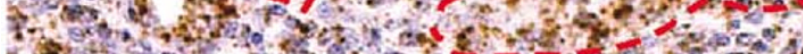

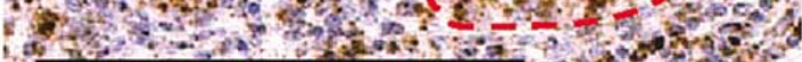

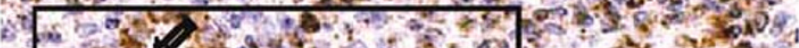

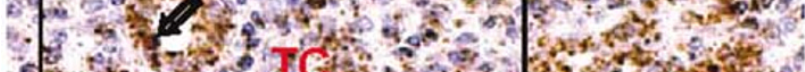
5 ring TG

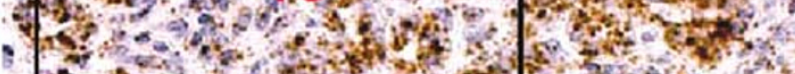

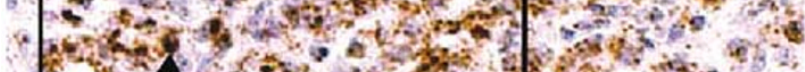

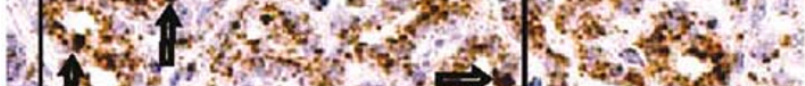

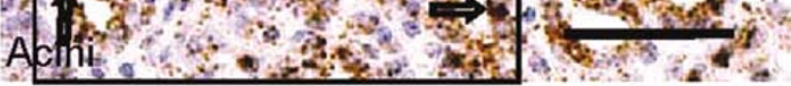
e Nestin in TC

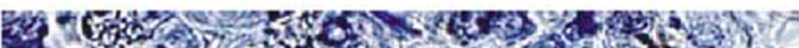
1.5. 3 . 3.

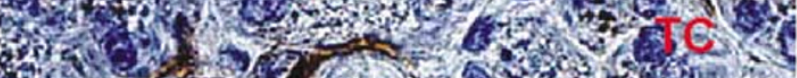

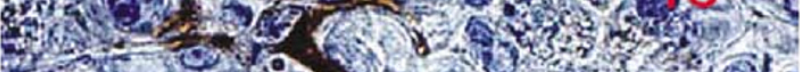

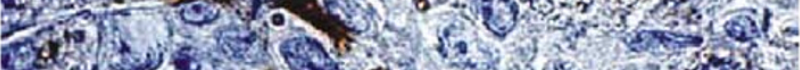

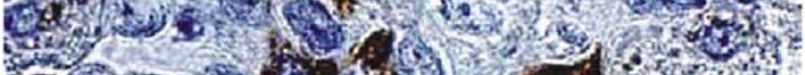
K.7.

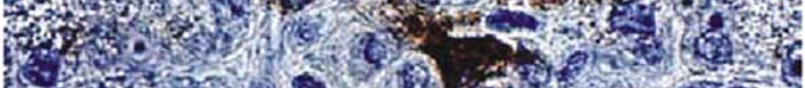

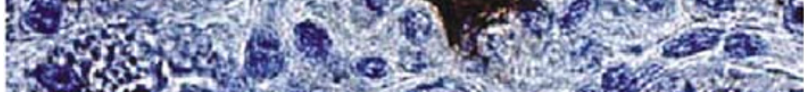

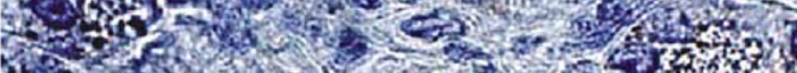

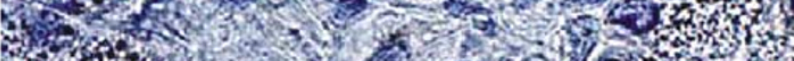

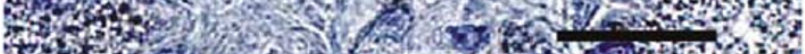

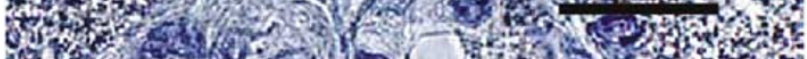

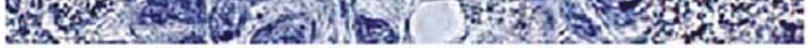

b HGF/c-Met in TC

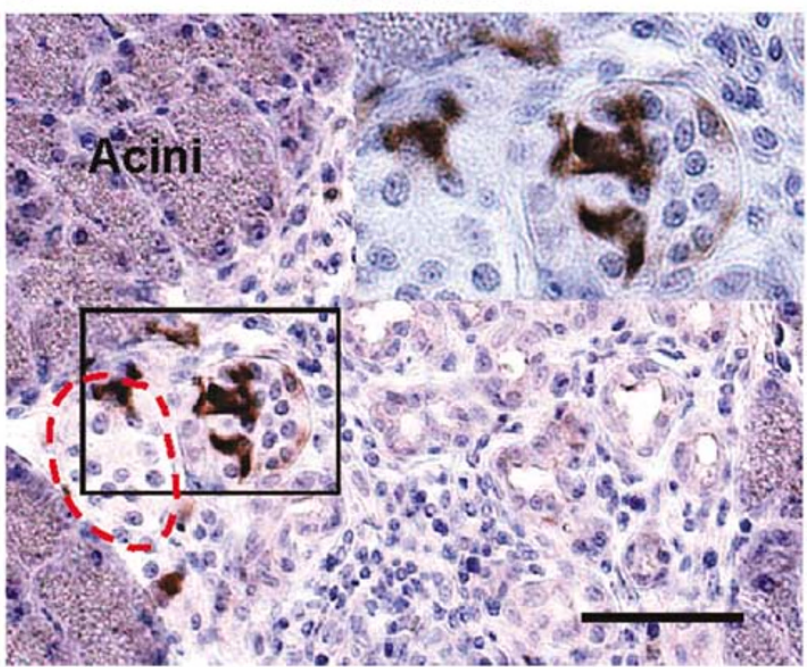

d

Ngn3: enlargement of box in (c)

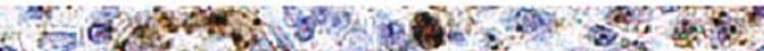

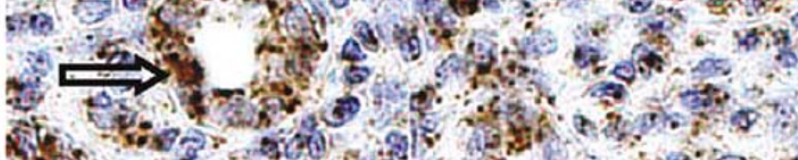

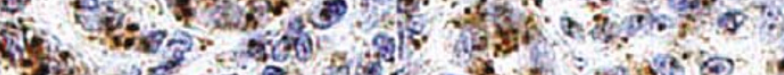

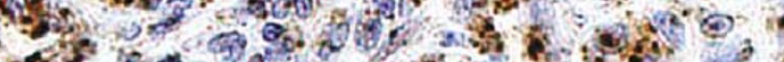

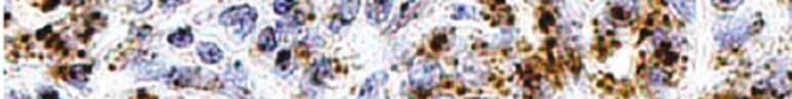

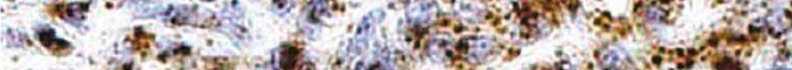

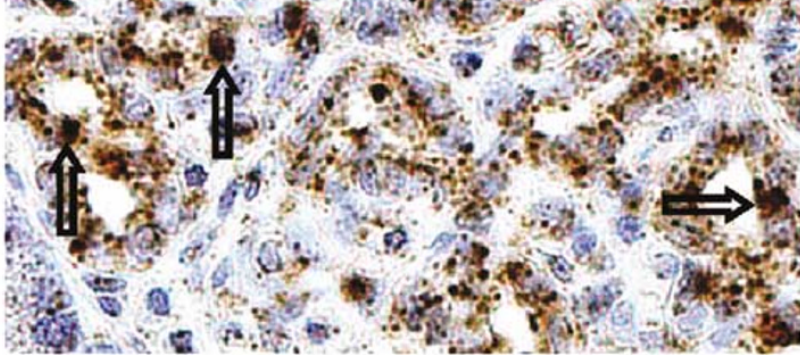
$f \quad$ PGP9.5 in TC

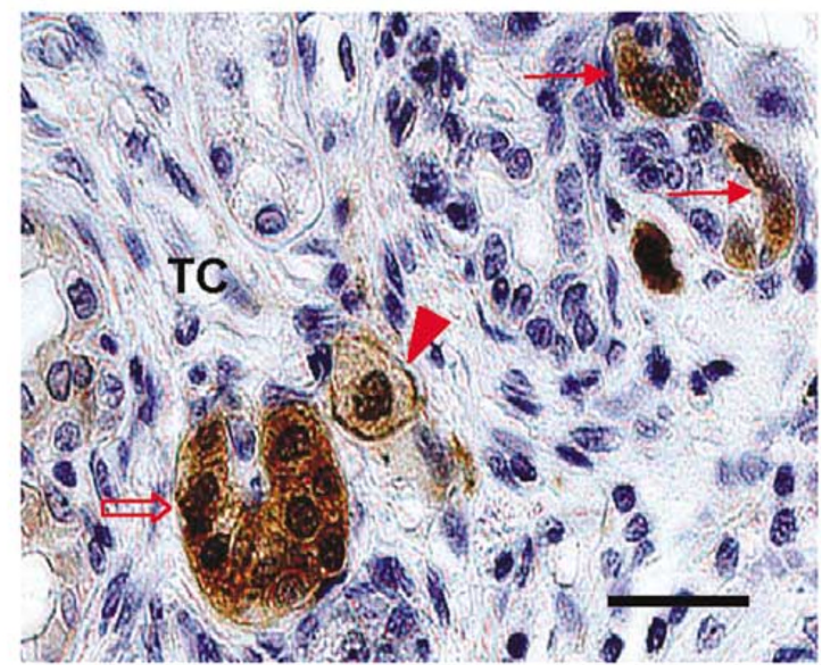


686

a

$\mathrm{CD}^{+}$and insulin ${ }^{+}$cells in a TC from an asymptomatic BBdp rat

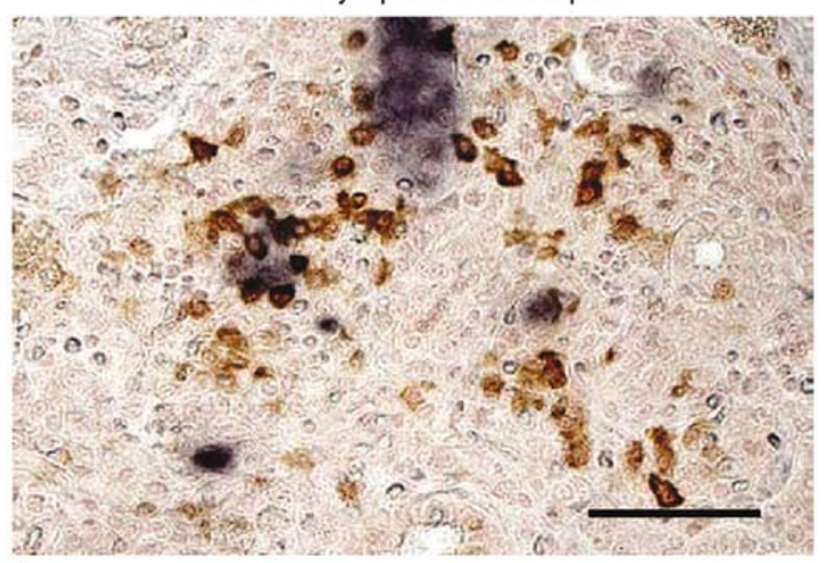

b

$\mathrm{CD}^{+} \mathrm{T}$-cells in a TC devoid of islets from a diabetic $B B$ rat

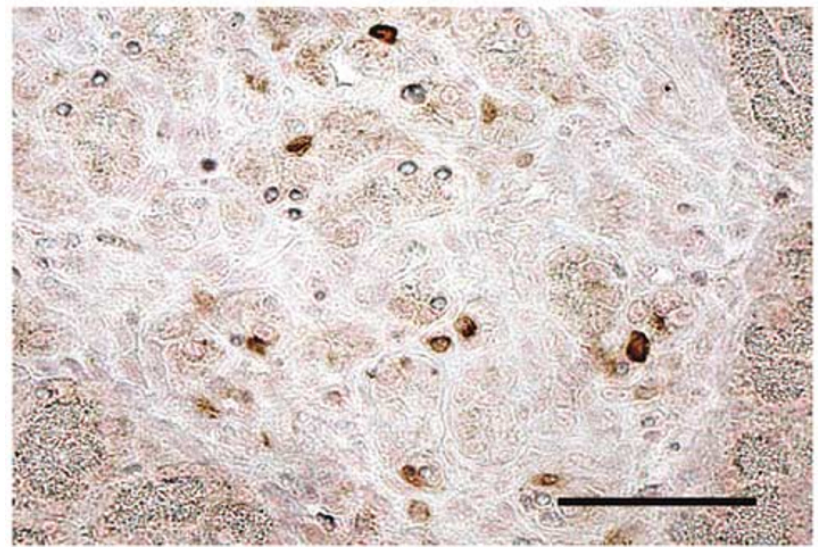

Figure $7 \mathrm{CD}^{+}$cells infiltrating into TC region. Infiltration of $\mathrm{CD}^{+}$cells in islets and TC in the pancreas of BBdp rats. Sections were first stained with rabbit anti-CD3 antibody using DAB as a substrate, then stained with guinea pig anti-insulin antibody using BCIP/NBT as a substrate, and counterstained with fast red. (a) $\mathrm{CD}^{+}$cells (dark brown) were observed in the TC area of an asymptomatic BBdp rat aged 148 days Note: $\mathrm{CD}^{+}{ }^{+}$cells in close proximity to insulin ${ }^{+}$(dark blue) cells, (b) $\mathrm{CD}^{+}$cells were observed in the TC area of a diabetic rat aged 108 days; no insulin $^{+}$cells were observed in the TC. Bar $=50 \mu \mathrm{m}$.

encountered. Our data support the proposal that acinar cells can transdifferentiate into other cell types, ${ }^{4,11,18,23}$ possibly by dedifferentiation into $\beta$ cells in vivo as observed in acinar cells of glucoseinfused Wistar rats. We cannot exclude the possibility that $\beta$-cells in the TC contribute to $\beta$-cell regeneration based on the present data.

With respect to the fate of TC and their islet cells, we frequently observed CD3 ${ }^{+}$cells in or around the TC in animals $\geq 60$ days. Insulin ${ }^{+}$cells occupied $\sim 19 \%$ of the TC in asymptomatic rats (Figures $1 \mathrm{~h}$, $3 \mathrm{a}-\mathrm{c}, 4 \mathrm{~d}, 7 \mathrm{a}$ ) but were essentially absent in TC from overt diabetic animals (Figure 7b). The lack of insulin ${ }^{+}$cells in the TC in overt diabetic rats and the presence of a T-cell infiltrate suggests that TC $\beta$ cells are targets of an autoimmune attack.
PDX-1 is a key transcription factor expressed in progenitor cells for the islets, acini and pancreactic ducts during embryogenesis of the pancreas and in the final differentiation of mature islet $\beta$ and $\delta$-cells. A subpopulation of ductal cells also express PDX-1, suggesting ductal epithelial cells are a potential source for $\beta$-cell neogenesis. PDX-1 was not only observed in ductal epithelium, but also in duct-like cells within TCs. More interestingly, PDX $-1^{+}$cells were observed budding from duct-like cells (Figure 5 ), further supporting the concept of duct-like cells as a source of $\beta$-cell progenitors. In support of this notion is the recent evidence from Kim et $a l^{44}$ showing that TC cultured in vitro gave rise to islet clusters after 3 days and these clusters responded to glucose challenge.

Ngn3 is a proendocrine bHLH transcription factor involved in endocrine and exocrine cell specification during embryogenesis, but whose function in adult pancreas remains controversial. ${ }^{42,45}$ Overexpression of Ngn3 can convert human pancreatic duct cells into insulin-expressing cells. ${ }^{45}$ In the present study, Ngn3 was detected in adult islets regardless of location and in the TC duct-like cells in animals of different ages. This finding is also consistent with the notion that islet cells and some duct-like cells in the TC of adult BBdp rats are endocrine progenitor cells.

Nestin $^{+}$cells have been reported not only in ducts but also in islets. ${ }^{36}$ In the present study, nestin $^{+}$staining was only found in cells located between the duct-like cells, probably stellate cells of mesenchymal origin. ${ }^{46}$ Other reports show that nestin $^{+}$cells in the pancreatic islets can transform into pancreatic endocrine, exocrine and hepatic cells after 90 days in culture. ${ }^{36}$ If nestin is a marker for stem cells in the pancreas, a point that is debated, ${ }^{47,48}$ the positive cells in the TC could be a source of stem cells for islet neogenesis.

PGP9.5 is expressed on all differentiated neuronal cells. It is also expressed in embryonic and adult pancreatic islet cells, neuronal cells and a few duct cells but is not normally expressed in acinar cells. In the present setting, PGP9.5 expression was observed in islets and neuronal cells as well as duct-like cells in the TC region. If TC ductlike cells are of acinar origin as some believe,${ }^{11}$ the expression of PGP9.5 is unexpected and suggests these cells could be endocrine progenitors. This finding is in agreement with Yokoyama-Hayashi et $a l^{38}$ that duct-like cells could function as progenitors for endocrine cell neogenesis under conditions of pancreatic injury as seen in the duct-ligation model. ${ }^{49}$

In summary, pancreatic TC occurred in parallel with the development of diabetes. These structures had the following characteristics: (1) high cell turnover, (2) decreased acinar phenotype (decreased expression of amylase), (3) presence of transitional cells with coincident keratin ${ }^{+} /$amylase $^{+}$(duct/ acinar) and keratin $^{+} /$insulin $^{+}$(duct/beta cells) 
expression, (4) progenitors in TC that are $\mathrm{Ngn}^{+}$, PGP9. $5^{+}, \mathrm{PDX}^{-1}{ }^{+}$, Nestin $^{+}$, (5) more insulin ${ }^{+}$cells in islets of TC from asymptomatic vs overt diabetic rats and (6) increased expression of duct epithelial markers, keratin and vimentin, which have been associated with duct-to-islet neogenesis. These data are consistent with islet neogenesis occurring from existing pancreatic cells via transdifferentiation. ${ }^{28,44}$ Thus, TC are unique structures that likely form in response to $\beta$-cell destruction and contain cells displaying markers of endocrine progenitors consistent with the possibility that, under the appropriate conditions, reconstitution of islet $\beta$-cells could occur by this route. It will be important to determine whether TC formation per se could be used to delay, prevent or reverse diabetes in the presence or absence of immunosuppressive agents.

\section{Acknowledgements}

We thank Dr Olga Pulido, Dr Rudy M Mueller and Peter Smyth, Pathology Section, Health Canada, for technical assistance and Jocelyn Souligny and Dominique Patry, Animal Resources Division, Health Canada, for animal care. We acknowledge Michael Steller, University of Ottawa for technical assistance. We also thank Dr Chris Wright, Vanderbilt University for sharing his anti-PDX-1 antibody, Dr Michael German, University of California San Francisco for anti-neurogenin 3 antibody and Dr Daniel Drucker, University of Toronto for GLP-1R antibody. This study was supported by the Juvenile Diabetes Research Foundation, Canadian Institute of Health Research, the Ontario Research and Development Challenge Fund and the Canada Foundation for Innovation.

\section{References}

1 Steele C, Hagopian WA, Gitelman S, et al. Insulin secretion in type I diabetes. Diabetes 2004;53:426-433.

2 Bonner-Weir S. Perspective: postnatal pancreatic beta cell growth. Endocrinology 2000;141:1926-1929.

3 Sharma A, Zangen DH, Reitz P, et al. The homeodomain protein IDX-1 increases after an early burst of proliferation during pancreatic regeneration. Diabetes 1999;48:507-513.

4 Bouwens L. Transdifferentiation versus stem cell hypothesis for the regeneration of islet beta-cells in the pancreas. Microsc Res Tech 1998;43:332-336.

5 Tokoro T, Tezel E, Nagasaka T, et al. Differentiation of acinar cells into acinoductular cells in regenerating rat pancreas. Pancreatology 2003;3:487-496.

6 Bockman DE. Toward understanding pancreatic disease: from architecture to cell signaling. Pancreas 1995;11:324-329.

7 Bockman DE. Cells of origin of pancreatic cancer: experimental animal tumors related to human pancreas. Cancer 1981;47:1528-1534.
8 Bockman DE, Boydston WR, Anderson MC. Origin of tubular complexes in human chronic pancreatitis. Am J Surg 1982;144:243-249.

9 Pound AW, Walker NI. Involution of the pancreas after ligation of the pancreatic ducts. I: a histological study. Br J Exp Pathol 1981;62:547-558.

10 Rosenberg L, Brown RA, Duguid WP. A new approach to the induction of duct epithelial hyperplasia and nesidioblastosis by cellophane wrapping of the hamster pancreas. J Surg Res 1983;35:63-72.

11 Bockman DE, Guo J, Buchler P, et al. Origin and development of the precursor lesions in experimental pancreatic cancer in rats. Lab Invest 2003;83:853-859.

12 Jimenez RE, Z'Graggen K, Hartwig W, et al. Immunohistochemical characterization of pancreatic tumors induced by dimethylbenzanthracene in rats. Am J Pathol 1999;154:1223-1229.

13 Rosenberg L, Duguid WP, Brown RA. Development of experimental cancer in the head of the pancreas by surgical induction of tissue injury. Am J Surg 1984; 147:146-151.

14 Bonner-Weir S, Baxter LA, Schuppin GT, et al. A second pathway for regeneration of adult exocrine and endocrine pancreas. A possible recapitulation of embryonic development. Diabetes 1993;42:1715-1720.

15 Lipsett M, Finegood DT. beta-cell neogenesis during prolonged hyperglycemia in rats. Diabetes 2002;51: 1834-1841.

16 Iovanna JL. Redifferentiation and apoptosis of pancreatic cells during acute pancreatitis. Int J Pancreatol 1996;20:77-84.

17 Wagner M, Luhrs H, Kloppel G, et al. Malignant transformation of duct-like cells originating from acini in transforming growth factor transgenic mice. Gastroenterology 1998;115:1254-1262.

18 Lardon J, Huyens N, Rooman I, et al. Exocrine cell transdifferentiation in dexamethasone-treated rat pancreas. Virchows Arch 2004;444:61-65.

19 Arias AE, Bendayan M. Differentiation of pancreatic acinar cells into duct-like cells in vitro. Lab Invest 1993;69:518-530.

20 De Lisle RC, Logsdon CD. Pancreatic acinar cells in culture: expression of acinar and ductal antigens in a growth-related manner. Eur J Cell Biol 1990;51: 64-75.

21 Hall PA, Lemoine NR. Rapid acinar to ductal transdifferentiation in cultured human exocrine pancreas. J Pathol 1992;166:97-103.

22 Rooman I, Heremans Y, Heimberg H, et al. Modulation of rat pancreatic acinoductal transdifferentiation and expression of PDX-1 in vitro. Diabetologia 2000;43: 907-914.

23 Bockman DE. Morphology of the exocrine pancreas related to pancreatitis. Microsc Res Tech 1997;37: 509-519.

24 Jia D, Otsuki M. Bezafibrate, a peroxisome proliferatoractivated receptor (PPAR)-alpha activator, prevents pancreatic degeneration in obese and diabetic rats. Pancreas 2003;26:286-291.

25 Scott FW, Cloutier HE, Kleemann R, et al. Potential mechanisms by which certain foods promote or inhibit the development of spontaneous diabetes in BB rats: dose, timing, early effect on islet area, and switch in infiltrate from Th1 to Th2 cells. Diabetes 1997;46: 589-598.

26 Wang GS, Gruber H, Smyth P, et al. Hydrolysed casein diet protects $\mathrm{BB}$ rats from developing diabetes by 
promoting islet neogenesis. J Autoimmun 2000;15: 407-416.

27 Rao PS, Mangipudy RS, Mehendale HM. Tissue injury and repair as parallel and opposing responses to CCl4 hepatotoxicity: a novel dose-response. Toxicology 1997;118:181-193.

28 Bouwens L. Islet morphogenesis and stem cell markers. Cell Biochem Biophys 2004;40:81-88.

29 Bulotta A, Di Cesare E, Ponte E, et al. Increased c-met expression during ductal beta cell neogenesis in experimental autoimmune diabetes. Growth Factors 2001;19:259-267.

$30 \mathrm{Gu}$ G, Brown JR, Melton DA. Direct lineage tracing reveals the ontogeny of pancreatic cell fates during mouse embryogenesis. Mech Dev 2003;120: 35-43.

31 Suzuki A, Nakauchi H, Taniguchi H. Prospective isolation of multipotent pancreatic progenitors using flow-cytometric cell sorting. Diabetes 2004;53: 2143-2152.

32 Calvo EL, Boucher C, Pelletier G, et al. Ontogeny of hepatocyte growth factor and c-met/hgf receptor in rat pancreas. Biochem Biophys Res Commun 1996;229: 257-263.

33 Jensen J, Heller RS, Funder-Nielsen T, et al. independent development of pancreatic alpha- and beta-cells from neurogenin3-expressing precursors: a role for the Notch pathway in repression of premature differentiation. Diabetes 2000;49:163-176.

34 Grapin-Botton A, Majithia AR, Melton DA. Key events of pancreas formation are triggered in gut endoderm by ectopic expression of pancreatic regulatory genes. Genes Dev 2001;15:444-454.

35 Schwitzgebel VM, Scheel DW, Conners JR, et al. Expression of neurogenin3 reveals an islet cell precursor population in the pancreas. Development 2000;127:3533-3542.

36 Zulewski H, Abraham EJ, Gerlach MJ, et al. Multipotential nestin-positive stem cells isolated from adult pancreatic islets differentiate ex vivo into pancreatic endocrine, exocrine, and hepatic phenotypes. Diabetes 2001;50:521-533.

37 Hunziker E, Stein M. Nestin-expressing cells in the pancreatic islets of Langerhans. Biochem Biophys Res Commun 2000;271:116-119.

38 Yokoyama-Hayashi K, Takahashi T, Kakita A, et al. Expression of PGP9.5 in ductal cells of the rat pancreas during development and regeneration: can it be a marker for pancreatic progenitor cells? Endocr J 2002;49:61-74.

39 Rooman I, Lardon J, Bouwens L. Gastrin stimulates beta-cell neogenesis and increases islet mass from transdifferentiated but not from normal exocrine pancreas tissue. Diabetes 2002;51:686-690.

40 Wilson ME, Scheel D, German MS. Gene expression cascades in pancreatic development. Mech Dev 2003; 120:65-80.

41 Kojima H, Fujimiya M, Matsumura K, et al. NeuroDbetacellulin gene therapy induces islet neogenesis in the liver and reverses diabetes in mice. Nat Med 2003;9:596-603.

$42 \mathrm{Gu}$ G, Dubauskaite J, Melton DA. Direct evidence for the pancreatic lineage: NGN3+ cells are islet progenitors and are distinct from duct progenitors. Development 2002;129:2447-2457.

43 Reid LE, Walker NI. Acinar cell apoptosis and the origin of tubular complexes in caerulein- induced pancreatitis. Int J Exp Pathol 1999;80:205-215.

44 Kim SY, Lee SH, Kim BM, et al. Activation of nestinpositive duct stem (NPDS) cells in pancreas upon neogenic motivation and possible cytodifferentiation into insulin-secreting cells from NPDS cells. Dev Dyn 2004;230:1-11.

45 Heremans Y, Van De Casteele M, in’t Veld P, et al. Recapitulation of embryonic neuroendocrine differentiation in adult human pancreatic duct cells expressing neurogenin 3. J Cell Biol 2002;159: 303-312.

46 Lardon J, Rooman I, Bouwens L. Nestin expression in pancreatic stellate cells and angiogenic endothelial cells. Histochem Cell Biol 2002;117:535-540.

47 Humphrey RK, Bucay N, Beattie GM, et al. Characterization and isolation of promoter-defined nestinpositive cells from the human fetal pancreas. Diabetes 2003;52:2519-2525.

48 Treutelaar MK, Skidmore JM, Dias-Leme CL, et al. Nestin-lineage cells contribute to the microvasculature but not endocrine cells of the islet. Diabetes 2003;52:2503-2512.

$49 \mathrm{Li} \mathrm{M}$, Miyagawa J, Moriwaki M, et al. Analysis of expression profiles of islet-associated transcription and growth factors during beta-cell neogenesis from duct cells in partially duct-ligated mice. Pancreas 2003;27:345-355. 